\title{
Overview of water resource assessment in South Africa: Current state and future challenges
}

\author{
WV Pitman* \\ 3 Reitz Crescent, Phalaborwa 1390, Limpopo, South Africa
}

\begin{abstract}
This paper reviews the progress made in the assessment of water resources in South Africa over the past 60 years by examining 5 major studies that were undertaken in this period. These studies illustrate how the exponential growth in computer power and the concomitant development of highly sophisticated tools have changed the manner in which our water resources have been appraised, allowing us to deal with more and more complex issues, including: water quality, surface water/groundwater interaction and the reduction in runoff due to afforestation and alien vegetation. However, the main concern today is the serious decline in hydrological monitoring in recent times. It is imperative that this decline be addressed, especially if we are to deal effectively with problems related to climate cycles and climate change, together with the deterioration in water quality.
\end{abstract}

Keywords: rainfall, streamflow, water resources, water quality, land use, climate cycles, climate change

\section{Introduction}

Water is arguably South Africa's most precious natural resource. The climate of South Africa is semi-arid with an average annual rainfall of $465 \mathrm{~mm}$, compared to the world average of $860 \mathrm{~mm}$. The total mean annual runoff (MAR) of South Africa (including Lesotho and Swaziland) is about $50 \times 10^{9} \mathrm{~m}^{3}-$ only $50 \%$ of the mean flow of the Zambezi River and a mere 3\% of that of the Congo River. A means of evaluating our meagre water resources is essential to planners and designers of water supply schemes and those responsible for their operation.

The first comprehensive assessment of South Africa's water resources was undertaken by Midgley (1952) in the 1950s - at around about the time that modern hydrology took off, aided by the development of the digital computer. Since then there have been 4 major studies. Each study has faced new challenges, but has also benefitted from the ongoing developments in computing and the availability of new tools. Where we stand today is a consequence of what has been done before - a prime example of the 'weight of history'. Accordingly, this paper presents summaries of the studies that have led us to where we are today. As was the case for each of the past studies, we now face new challenges. The decline in the monitoring of rainfall and streamflow, coupled with the growing impact on rivers of land use, much of it poorly documented, are just two of the problems that face us today.

\section{Review of previous studies}

Five major studies undertaken over the past six decades are discussed briefly in this section. The studies are compared from the point of view of available data, techniques applied and

This paper was originally presented at the Water Research

Commission 40-Year Celebration Conference, Kempton Park,

31 August - 1 September 2011.

* To whom all correspondence should be addressed.

용 +27 82330 4630; e-mail: pitmanwv@iafrica.com results achieved. Particular emphasis is given to the evolution of the computer as an analysis tool over the decades.

\section{The 1952 study}

This study by Midgley (1952) was undertaken prior to the advent of the computer age in South Africa. All calculations were done manually or with the aid of adding machine or slide rule. Graphical techniques were widely employed. Of the 400 or so flow records available at the time only about half were suitable and only 30 records were available for periods longer than 30 years. Missing annual flows were filled in by simple graphical correlations between flow and so-called district rainfall. Long-term MAR was derived from the mean of the measured and infilled annual flows. MAR (expressed in $\mathrm{mm}$ ) was plotted on log-log paper against catchment MAP (mean annual precipitation) to derive MAP-MAR relationships for un-gauged catchments.

Relationships between reservoir storage and yield were derived with the mass curve or Rippl (1882) diagram. This gave the yield sustainable over the record period - analogous to what we now call the historical firm yield. The storage-yield curves were rendered dimensionless by dividing by MAR and were sorted into groups displaying similarities and mean curves were derived for each group, which represented a 'climatological zone'.

The 1952 survey also provided useful information on perennial rivers, monthly flow duration curves for each zone, a sediment map and a reliability map.

\section{The 1969 study}

This study by Midgley and Pitman (1969), was done with the benefit of a main-frame computer (single user), although it was not nearly as powerful as today's personal computers (PCs). The standard means of communication with the computer was via punch card.

The first step in this study was to take the catchment subdivision system (primary, secondary and tertiary) of the 
Department of Water Affairs (DWA) to the next level by subdividing tertiary catchments into quaternary units. The quaternary information was fed into the computer by overlaying on a $1^{\prime}$ by $1^{\prime}$ grid and assigning a catchment code to each grid point. The grid was also overlaid on a rainfall map to capture MAP at each point. A punch card was produced for each of the nearly half a million grid points covering South Africa. Catchment areas were computed by summing the number of grid points with the same code and correcting for latitude. Catchment MAPs were derived by averaging the MAPs at each point in the catchment.

In this study 138 flow records were used, which was somewhat lower than the number used in the 1952 survey. Part of the reason for the reduced number was the need to confine the statistical analyses to relatively long records, but certainly land-use developments in several of the gauged catchments led to the rejection of many. In any event, the shorter monthly records were extended by correlation with catchment rainfall, done by computer.

The necessity of introducing the concept of risk was recognised for this study in the determination of relationships between reservoir storage and yield. This was achieved by first scanning each record to abstract independent sequences ranging from 1 month to 96 months. Return periods were assigned to the data and smooth curves were fitted to derive a relationship among return period (i.e. probability), duration and cumulative flow, which was expressed as a percentage of MAR By overlaying these curves it was possible to detect regional similarities and for each regional group a set of average curves was produced.

For each region it was possible to construct theoretical inflow sequences of up to 96 months for a range of return periods ranging from 5 years to 100 years and to derive storage for a given draft by mass balance. The outcome was a set of storage-draftfrequency diagrams - one for each region.

The relationship between MAR (expressed in $\mathrm{mm}$ ) and MAP was derived for each gauged catchment and zones of similar rainfall-runoff characteristics were identified. The equations for each zone were used to convert MAP to MAR at each grid point and the MARs were summated for each quaternary catchment.

\section{The 1981 study}

This study by Midgley et al. (1981) was undertaken prior to the advent of the personal computer (PC). The computing environment was that of large, main-frame computers linked to a number of remote terminals.

When this study was initiated it was recognised that the question of land use could no longer be ignored by simply rejecting all records affected by growing land use. To overcome this problem a deterministic rainfall-runoff model developed by Pitman (1973) was employed. Not only could it be used to extend flow records (as dictated by the availability of suitable rainfall records) but it could also be used to facilitate the process whereby records affected by land use could be 'naturalised' by removing the effects of irrigation, afforestation and all water transfers. This enabled the research team to use 334 flow records - considerably more than the number used in the previous 2 studies; however, many of the additional records were from new gauges.

Regionalisation into hydrologically similar zones was accomplished by mapping the Pitman model parameters and then simulating time series of natural monthly flows for each quaternary catchment. The simulation period was from 1920 to
1976. The density of rain gauges prior to 1920 was considered to be too sparse and 1976 was the last complete year of data at the onset of the study in the late 70s. Thereafter, compilation of regional storage-draft-frequency curves was done in similar fashion to that used in the 1969 study.

\section{The 1994 study (WR90)}

By the time this study (by Midgley et al., 1994) was initiated the PC had become a useful and versatile analysis tool. In addition, geographical information systems (GIS) software was already being used for a wide range of applications.

The first major decision of the study team was to redefine the quaternary catchment boundaries (and their numbering system) for 3 reasons, namely:

- The original boundaries (used for the 1969 and 1981 studies) were drawn to the relatively coarse scale of 1 in 500000

- The original quaternaries were based on a more or less equal area concept, whereas it was considered preferable to vary catchment size according to runoff - the higher the runoff the smaller the area (especially in mountainous regions) and vice versa

- There was some conflict between the numbering system and that used by DWA for its primary, secondary and tertiary catchments.

By this time DWA had digitised primary, secondary, tertiary and gauged catchments from 1 in 50000 topographical maps. These boundaries were superimposed on 1 in 250000 maps to enable the team to add quaternary boundaries, which were digitised and incorporated into the GIS coverage. A total of 1956 quaternary catchments were created, ranging in size from about $100 \mathrm{~km}^{2}$ in mountainous, high-rainfall areas to several thousand square kilometres in the arid north-western interior. The GIS was used to determine the average MAP of each quaternary by overlaying a $1^{\prime}$ by $1^{\prime}$ grid of MAP values created by Natal University, Department of Agricultural Engineering, Pietermaritzburg (Dent et al., 1989).

Another major decision was to develop a PC-based version of the Pitman rainfall-runoff model to facilitate calibration, particularly in developed catchments. The new model, called WRSM90 (Pitman and Kakebeeke, 1991), was of modular construction with 4 types of module - runoff, irrigation, reservoir and channel. Land-use components handled by the model were allowed to vary over time to mimic the actual historical changes that had taken place over the period of simulation. These land-use features included irrigation, afforestation, urbanised areas, reservoirs (either single or equivalent reservoir made up of a number of small dams), abstractions, return flows and water transfers in or out of the catchment.

The ability of the WRSM90 model to handle complex catchments, together with the opening of several new gauges, enabled the study team to calibrate on 483 flow records, compared with the 334 used in the 1981 study.

Regionalisation of model parameters followed along similar lines to those of the 1981 study, with the exception that GIS could be used to overlay various features on the quaternary catchment map to facilitate the regionalisation process. After regionalisation the WRSM90 model was used to simulate 70 -year time series of natural flow for each quaternary catchment, covering the period 1920 to 1989.

Compilation of regional storage-draft-frequency curves was done in similar fashion to the 1981 study, with the 
exception that more emphasis was placed on the 70 -year simulated time series since they all covered the same epoch, whereas the observed (naturalised) records covered different periods and many were too short for meaningful statistical analysis.

All three of the earlier studies produced various maps depicting information relevant to each survey. However, by far the most comprehensive set of maps was issued in the 1994 survey. These maps, produced on the project's GIS and overlaid with the quaternary boundaries, contained the following information: base map, rainfall, evaporation, runoff, land cover and water use, WRSM90 model parameters, geology, soils, sediment yield and vegetation. The maps were printed to a scale of 1 in 1000000 and 24 maps were needed to cover the entire study area, i.e. a total of 240 maps for the 10 coverages.

\section{The 2008 study (WR2005)}

This study (Middleton and Bailey, 2008) was preceded by a number of workshops, in which the opinions of a number of practising hydrologists were sought. As a result it was decided that the interaction between surface water and groundwater needed to be included in the modelling process, that water quality issues needed to be addressed and that runoff reduction by afforestation and alien vegetation required attention.

The first major task in the study was the comprehensive upgrade to the WRSM2000 model (Pitman et al., 2008) - the Windows version of the WRSM90 model used in the 1994 survey. These upgrades included the following:

- Modelling of the surface water/groundwater process by Sami (2005) and Hughes (2004) methodology

- Improved modelling of the impact of afforestation

- Improved modelling of irrigation

- Improved modelling of wetlands

- Modelling of the impact of alien vegetation

- Modelling of the impact of mining areas (addition of a mining module)

Thereafter the study proceeded along similar lines to that of the WR90 study, with the main exception that storage-draftfrequency curves were not produced, as it was assumed that storage-yield analyses would by now be undertaken on computer. Water quality was addressed with the aid of a new model, SALMOD (Herold and Nyland, 2011), to analyse stressed catchments, and a spreadsheet model was used for all catchments in South Africa and Lesotho.

The main innovation was the issue of a DVD with a 'dashboard' (menu system) containing all the models, electronic maps, spreadsheets, monthly time-series data files of point rainfall, catchment rainfall and natural flows, reports, WRSM2000 networks and associated data files. The disk includes ARCGIS so that the user can manipulate the various maps and coverages, unlike WR90 where only printed maps were available. Also included is Hughes' SPATSIM (Middleton and Bailey, 2008) which, inter alia, allows one to determine ecological water requirements (EWRs).

\section{Review of the present situation}

The past 60 years has seen a huge growth in many aspects that influence our approach to water resource assessment, in particular, the explosive growth in computer power. It is generally recognised that computing power has doubled every 2 years since the first computers were built. This translates to a

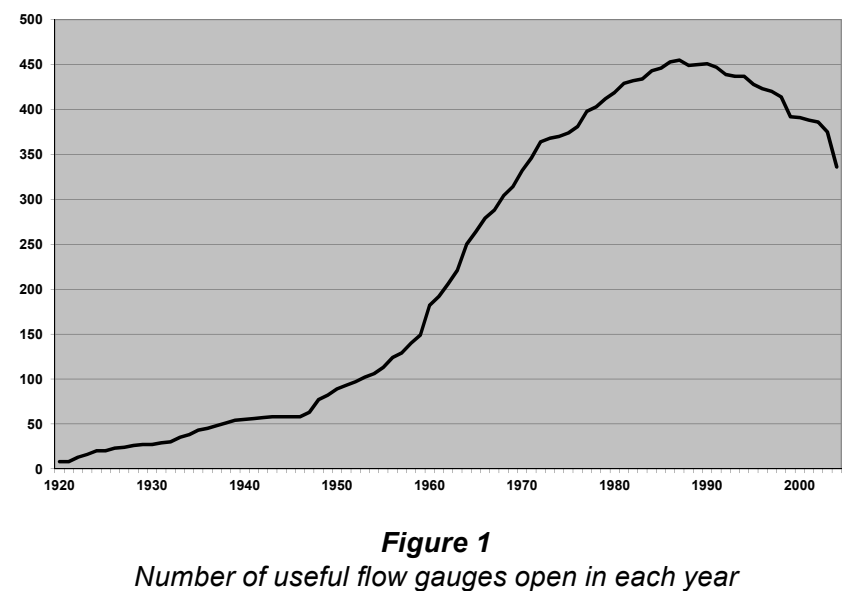

1 billion times increase in power over 60 years. This power, in conjunction with the development of new computer-based applications and their availability on the internet (e.g. Google Earth) has given us the ability to undertake analyses that were unheard of at the dawn of the computer age. However, all of the computing power in the world is useless without the appropriate data to be processed.

Two of the primary sources of hydrological data are rainfall and river flow. Collection of rainfall data is a prime responsibility of the South African Weather Service (SAWS), who, to a large extent, relies on ordinary citizens to read their gauges each morning and send the data to SAWS for processing. The Department of Water Affairs (DWA) is responsible for the monitoring of river flow and reservoir balances throughout the country and this requires many people of different skills - from those who design and build gauging weirs to those who process the recorder charts to build up records of flow and those who disseminate the information to the users.

In the brief discussions on the past surveys it was shown how the number of useful flow records had increased since 1969 , which is an encouraging sign. However, if we examine the number of useful gauges open in each year (as derived from the flow data set used in WR2005) there is a cause for concern, as shown in Fig. 1. This figure shows a rapid growth after a relatively slow start before 1960 , and then a flattening off to a peak of around 450 in the late 1980s. Since 1990 there has been a steady decline such that the number open in 2004 has dropped to about 350 . If this trend continues into the future it will be a serious cause for concern.

A graph of the number of (useful) rain gauges open paints a far more serious picture - see Fig. 2. When the use of time series of flow was first adopted in the 1981 survey, the period prior to 1920 was rejected owing to the relative scarcity of stations open before that date. However, we are now in a similar position with the decline in numbers from a high around 1970 to only about half of that in 2004 , which is roughly the same number of stations as in 1920 . This is a major problem as rainfall is the primary input to WRSM2000 (or any other rainfallrunoff model) - not only for simulating runoff but also for calculating irrigation demands and losses from reservoirs and wetlands. Some water management areas (WMAs) are worse off; for example, WMAs No. 4 (Olifants) and No. 13 (Upper Orange) now have less than half the number of stations open than was the case in 1920.

The various components of catchment land use have also exhibited a huge growth since the first survey in 1952, when the total use (including evaporation from dams) was estimated to 


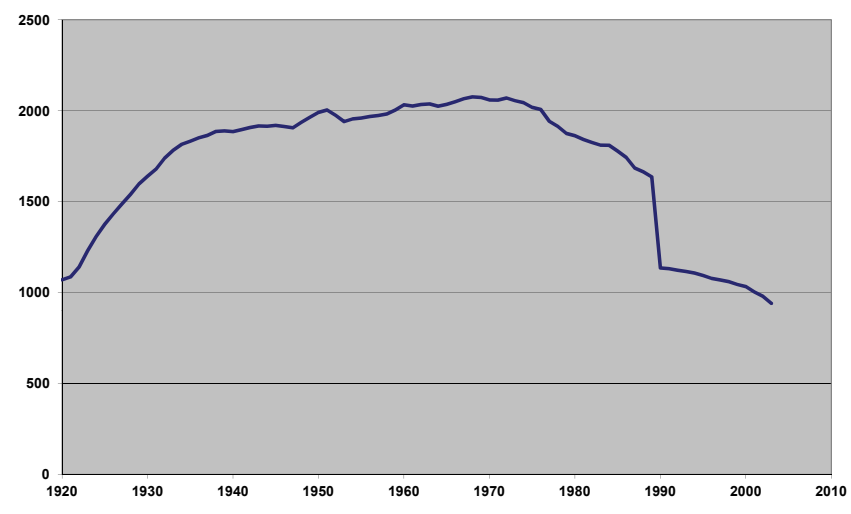

Figure 2

Number of rainfall stations open in each year

Growth in number of large dams

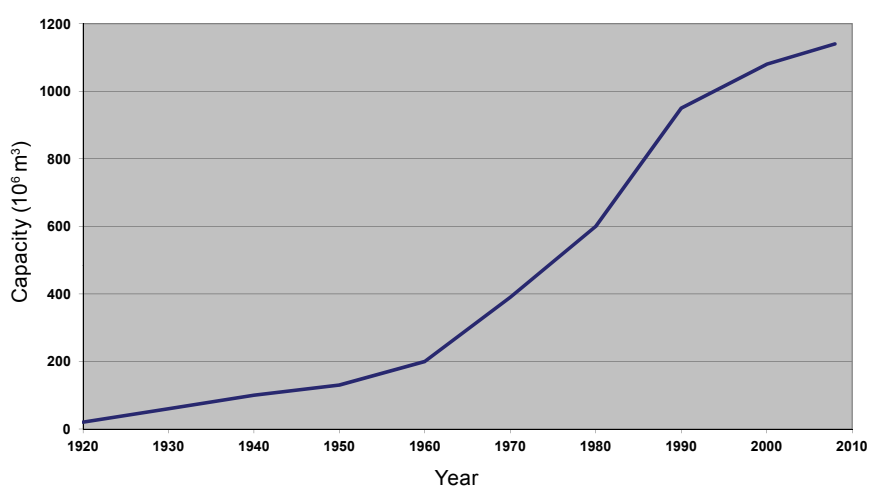

Figure 3

Cumulative dam capacity vs. time

be less than $3500 \times 10^{6} \mathrm{~m}^{3} / \mathrm{a}$ or about $7 \%$ of total MAR. Since then it has grown considerably. By the turn of the century total annual water demand exceeded $13000 \times 10^{6} \mathrm{~m}^{3}$, to which must be added a further $3000 \times 10^{6} \mathrm{~m}^{3}$ (estimated evaporation loss from dams), bringing total water use to $16000 \times 10^{6} \mathrm{~m}^{3} / \mathrm{a}$. A graph showing the growth in total large dam capacity is indicative of the growth in water resource development for the entire country (see Fig. 3). The graph, produced by SANCOLD (2009), shows a very rapid growth in the 1970s (mainly due to the Orange River and Thukela-Vaal projects). There has been a progressive decline in large dam development since 1980. To this must be added the countless farm and other small dams that are spread across the country.

Irrigation has always been the main water user and still accounts for about $60 \%$ of total use in South Africa, despite the ever-growing demands for industrial, mining and residential purposes. While there are large irrigation schemes, much of the water flow for irrigation belongs to individual farmers and data on such areas are usually sparse.

Abstractions and return flows have grown considerably but the records of such are in the hands of individual concerns and local authorities, whose enthusiasm for monitoring usually falls way behind that of the DWA.

Areas of afforestation are reasonably well documented and research is ongoing into the reduction of flow by the various tree types. The encroachment of alien vegetation is a relatively new factor and little is known about the growth in extent over time. More work also needs to be done on its impact on flows, particularly in the riparian zone.
The present scenario is thus one of burgeoning computer power, coupled with a decline in the monitoring of hydrological data, compounded by ever-growing land use, much of it poorly documented. This situation, together with other factors, brings us to the subject of challenges that will face us in the future.

\section{Future challenges}

Before we contemplate these challenges it is important to appreciate why we need to examine past hydrological records. We know that history does not repeat itself but our water resource planning is based on the premise that - after all manmade influences have been removed - the hydrological characteristics will remain essentially the same. There has been much discussion of late on the subjects of climate change and climate cycles, which imply that the future could be quite different to the past, hydrologically speaking. More will be said about this later.

In their article, Strategic planning for water resources in South Africa, Van Rooyen et al. (2009) state that: 'What is important is that the monitoring of rainfall and runoff must be continued vigorously and the monitoring network must be improved to ensure that the actual effects of climate change are measured accurately and brought into the analysis of (water) resources as quickly as possible.' This statement holds true even without the threat of climate change (see Figs. 1 and 2).

Monitoring requires the services of suitably qualified people and here there is real cause for concern. In his article, 'The water crisis in South Africa', Herold (2010) rates the loss of essential skills as a major threat and states by way of example that only $39 \%$ of DWA's engineering posts were filled in 2008 and that the situation will deteriorate further with the retirement of senior personnel. In the same article Herold states that infrastructure leakage in urban areas has reached crisis proportions. While this has serious implications for water demand management it also means that a large quantity of unmetered water is finding its way into our surface water and groundwater systems. The problem of water theft must fall under the umbrella of monitoring - or the lack thereof. Herold (2010) quotes the example of the theft of about $175 \times 10^{6} \mathrm{~m}^{3} / \mathrm{a}$ of irrigation water by farmers in the Upper Vaal catchment. He lays the blame for the failure to define water rights, to enforce monitoring, to interpret readily available information and to enforce compliance on the 'crumbling capacity within the DWA.'

The worsening of water quality is another factor to be addressed more vigorously in future studies. Van Rooyen et al. (2009) state that: 'deterioration of water quality is a huge threat and will have to receive a lot of attention.' After all, water that is too heavily polluted for use is as bad as having no water at all. A start was made in the WR2005 project and future studies will no doubt include a much larger water-quality component.

WR2005 was the first survey of water resources to address the question of the interaction between surface water and groundwater. However, much work still needs to be done to improve the modelling process and the mapping of hydro-geological parameters across the entire country. Some additional work on WR2005 has just been completed with the main tasks being to improve patching of observed flows, a Visio system for producing WRSM2000 network diagrams and graphical enhancements to SALMOD.

One of the main problems with past assessments is the large time gap between successive studies - of the order of 12 years to 15 years. To overcome this shortcoming the WRC will initiate a new study in 2012. This study will include updating 
of all hydrological data up to 2010, further enhancements to WRSM2000, revised groundwater data, monthly time series of present-day flow, recommendations for improved monitoring and a web-based menu system.

Environmental water requirements have become an important component of the hydrological cycle, thus it is imperative that future studies provide information that is adequate for the determination of such requirements.

Unlike climate change, discussions on climate cycles have been around for a very long time. In the Bible, Genesis 41:29-30 states: 'Behold, there will be seven years of plenty throughout the land of Egypt: and there shall arise after them seven years of failure.' This was nearly 4000 years ago! In more recent times Alexander (2007) has examined hydrological data in South Africa and is convinced that such cycles exist. He states: 'Neither the lengths of the periods or the synchronous occurrences are precise in the mathematical sense but their presence is beyond doubt.' If these cycles do exist, and if their patterns will remain essentially the same, the historical data should still be relevant. The main challenge here is on the shoulders of water resource engineers to accommodate the influences of such cycles.

What is of greater concern is the possibility of climate change. There has been much argument concerning the existence or otherwise of climate change in recent years. Prof. Grant Cawthorn of Wits University School of Geosciences (Creamer, 2011) states: 'climate change is probably the world's biggest distraction.' It is unfortunately more than a mere distraction, with huge sums of money being earmarked for cutting carbon emissions, when the jury is still out as to whether global warming is anthropogenic or part of a natural cycle. We know from history that the world climate has not always been constant. The Medieval Warm Period (900-1300) and the Little Ice Age (1350-1850) are the two most recent examples. Alexander et al. (2007) have studied the linkages between solar activity, climate predictability and water resource development. One of their main conclusions is that there are fundamental flaws in current global climate models used for climate change applications. Global climate change models also show a huge variation in their predictions and work to improve them is ongoing. Alexander (2007) also remarks on the 'totally unprofessional attempts to silence those who hold the view that human activities are not the principal cause of climate change' - strong words indeed! The arguments and counter-arguments on climate change must not be allowed to distract us from the main goals of water resource assessment. There is no substitute for good data and the plea for improved monitoring by Van Rooyen et al. (2009) and DWA et al. (2011) must not fall upon deaf ears.

\section{Summary and conclusions}

Water resource assessment in South Africa over the last 60 years has become more and more complex due to burgeoning growth in land use, deterioration in water quality and the need to examine the interaction between surface water and groundwater. The exponential growth in computing power and the concomitant development of appropriate tools has enabled us to handle these complexities, but there is now a serious concern regarding the monitoring of hydrological data. Both rainfall and river flow measurement have exhibited a decline over recent years and the situation with rainfall is particularly serious, where our monitoring network has declined from a high in the 1970s to a current situation where the network is no better than it was as far back as 1920. The growth in land use has exacerbated the problem, due to poor or non-existent monitoring.

Accordingly, one of the main challenges for the future will be to get the hydrological monitoring 'back on track' and this can only be done by recruitment of suitable personnel and the allocation of adequate funds. We should not allow ourselves to be distracted by the ongoing arguments concerning climate change, but should rather analyse its effect - if any - by accurate measurements with an improved hydrological monitoring network.

Future studies will also need to take a closer look at water quality and the interaction between surface water and groundwater. The possibility of climatic cycles and climate change must not be overlooked, but should not be allowed to distract us from the main goals.

\section{References}

ALEXANDER WJR (2007) Water resources and climate change. Civil Engineering 15 (6) 34-36. The South African Institution of Civil Engineering (SAICE). URL: http://www.civils.org.za/Publications/ CivilEngineeringMagazine/MonthlyIssues/tabid/84/Default.aspx.

ALEXANDER WJR, BAILEY F, BREDENKAMP DB, VAN DER MERWE A and WILLEMSE N (2007) Linkages between solar activity, climate predictability and water resource development. J. SAICE 49 (2) 32-44.

CREAMER M (2011) Climate change 'possibly our biggest distraction'. Quoting Prof. Grant Cawthorn in a Mining Weekly Online video interview, 10 March 2011. URL: http://www.miningweekly. com/article/wits-platinum-prof-downgrades-climate-change-toworlds-big.

DENT MC, LYNCH SD and SCHULZE RE (1989) Mapping mean annual and other rainfall statistics in Southern Africa. ACRU Report No. 27, WRC Report No. 109/1/89. Water Research Commission, Pretoria, South Africa.

DWA and contributing authors (2011) Data and Information SubStrategy for National Water Resource Strategy, Version 2. Department of Water Affairs, Pretoria, South Africa.

HEROLD CE (2010) The water crisis in South Africa. Civil Engineering 18 (5) 6-15. The South African Institution of Civil Engineering (SAICE). URL: http://www.civils.org.za/Publications/ CivilEngineeringMagazine/MonthlyIssues/tabid/84/Default.aspx.

HEROLD CE and NYLAND G (2011) Water Resources of South Africa 2005 (WR2005) SALMOD Model. WRC, Pretoria.

HUGHES DA (2004) Incorporating groundwater recharge and discharge functions into an existing rainfall-runoff model. Hydrol. Sci. J. 49 (2) 297-311.

MIDDLETON BJ and BAILEY AK (2008) Water Resources of South Africa2005. WRC Report Nos. TT 380 to 382/08. Water Research Commission, Pretoria, South Africa.

MIDGLEY DC (1952) A Preliminary Survey of the Surface Water Resources of the Union of South Africa. Unpublished Ph. D. Thesis. University of Natal, Pietermaritzburg, South Africa.

MIDGLEY DC and PITMAN WV (1969) Surface Water Resources of South Africa. HRU Report No. 2/69. Hydrological Research Unit, University of the Witwatersrand, Johannesburg, South Africa.

MIDGLEY DC, PITMAN WV and MIDDLETON BJ (1981) Surface Water Resources of South Africa. HRU Report Nos. 8/81 to 13/81. Hydrological Research Unit, University of the Witwatersrand, Johannesburg, South Africa.

MIDGLEY DC, PITMAN WV and MIDDLETON BJ (1994) Surface Water Resources of South Africa 1990. WRC Report Nos. 298/1/94 to 298/6.2/94. Water Research Commission, Pretoria, South Africa. PITMAN WV (1973) A Mathematical Model for Generating Monthly River Flows from Meteorological Data in South Africa. HRU Report No. 2/73. Hydrological Research Unit, University of the Witwatersrand, Johannesburg, South Africa.

PITMAN WV and KAKEBEEKE JP (1991) WRSM90 User's Guide. Stewart Scott Inc., Johannesburg, South Africa. 
PITMAN WV, KAKEBEEKE JP and BAILEY AK (2008)

WRSM2000 (enhanced) Water Resources Simulation Model for Windows, User's Guide. WRC, Pretoria.

RIPPL W (1882) Water supply of Vienna. Proc. Inst. Civ. Eng. 71.

SAMI K (2005) Technical Documentation for Surface-Groundwater Interaction for Use in System Models. DWA draft report (unnumbered). DWA, Pretoria, South Africa.

SANCOLD (2009) South African Register of Large Dams. Civil
Engineering 17 (5) 50-55. The South African Institution of Civil Engineering (SAICE). URL: http://www.civils.org.za/Publications/ CivilEngineeringMagazine/MonthlyIssues/tabid/84/Default.aspx.

VAN ROOYEN J, VAN NIEKERK P and VERSVELD R (2009)

Strategic planning for water resources in South Africa. Civil Engineering 17 (5) 5-8. The South African Institution of Civil Engineering (SAICE). URL: http://www.civils.org.za/Publications/ CivilEngineeringMagazine/MonthlyIssues/tabid/84/Default.aspx. 